\title{
Techno-Economic Analysis of Indian Draft Standard Levels for Room Air Conditioners
}

Michael A. McNeil and Maithili Iyer

\author{
Energy Analysis Department \\ Environmental Energy Technologies Division \\ Lawrence Berkeley National Laboratory
}

March 2007

USAID funded this report via the Office of Energy and Information Technology within the Global Bureau for Economic Growth, Agriculture and Trade, through the U.S. Department of Energy under Contract No., DE-AC03-76SF00098.. 


\section{Table of Contents}

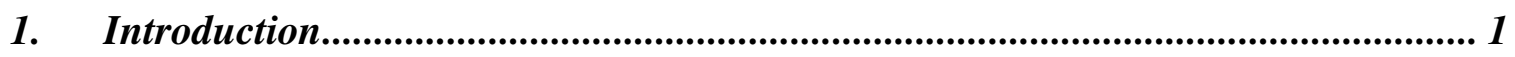

2. BEE Draft Standards .................................................................................... 2

$2.1 \quad$ Comparison with International Levels.................................................................. 3

2.2 Current Market and Impact of Standards ................................................................ 5

3. Cost Effectiveness ........................................................................................ 8

3.1 Cost Efficiency Relationship ........................................................................................ 9

3.2 Consumer Financial Impacts ........................................................................................ 10

4. National Energy Savings ...................................................................................... 14

4.1 Efficiency Scenarios ..................................................................................................... 14

4.2 Market Forecast ............................................................................................................ 16

4.3 National Energy Consumption ........................................................................... 18

4.4 Environmental Impacts ..................................................................................... 19

4.5 National Financial Impacts ..................................................................................... 20

5. Conclusions …................................................................................................ 22 


\section{List of Figures}

Figure 1 - MEPS for 1.5 ton Window Air Conditioners - 1994-2010 ...................... 4

Figure 2 - Air Conditioner Test Data and Rating Plan - 2007 ............................. 6

Figure 3 Life Cycle Cost of Window AC Design Options ....................................... 13

Figure 4 - Market Evolution of Efficiency .............................................................. 16

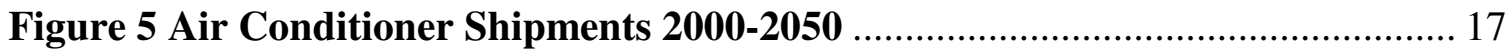

Figure 6 -Air Conditioner Electricity Consumption Scenarios ............................. 18

Figure 7 - Net Present Value of Savings due to Standards and Labeling Scenario .. 21

\section{List of Tables}

Table 1 BEE Rating Scheme for Room Air Conditioners (Window and Split).

Table 2 Tested Energy Efficiencies of the Most Popular 1.5 Ton ACs in India in 2006

Table 3 Estimated Market-wide Impacts of MEPS Only ...................................... 7

Table 4 Cost-Efficiency Relationship for Indian Window Air Conditioners ............ 10

Table 5 Cost-Effectiveness of Energy Efficiency - Commercial Customers ............. 12

Table 6 Cost-Effectiveness of Energy Efficiency - Residential Customers ............... 12

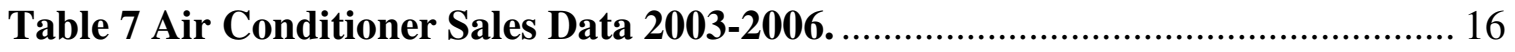

Table 8 Site Energy Consumption and Savings 2010-2030 .................................. 19

Table 9 Primary Energy and Emissions Savings 2010-2030 ................................. 20

Table 10 - Cumulative NPV of Financial Impacts of Efficiency Scenarios ............. 22 


\title{
Techno-Economic Analysis of Indian Draft Standard Levels for Room Air Conditioners
}

\author{
Michael McNeil and Maithili Iyer
}

\section{Introduction}

The Indian Bureau of Energy Efficiency (BEE) finalized its first set of efficiency standards and labels for room air conditioners in July of 2006. These regulations followed soon after the publication of levels for frost-free refrigerators in the same year. As in the case of refrigerators, the air conditioner program introduces Minimum Efficiency Performance Standards (MEPS) and comparative labels simultaneously, with levels for one to five stars. Also like the refrigerator program, BEE defined several successive program phases of increasing stringency.

In support of BEE's refrigerator program, Lawrence Berkeley National Laboratory (LBNL) produced an analysis of national impacts of standards in collaboration with the Collaborative Labeling and Standards Program (CLASP). That analysis drew on LBNL's experience with standards programs in the United States, as well as many other countries. Subsequently, as part of the process for setting optimal levels for air conditioner regulations, CLASP commissioned LBNL to provide support to BEE in the form of a techno-economic evaluation of air conditioner efficiency technologies. This report describes the methodology and results of this techno-economic evaluation. The analysis consists of three components:

- Cost effectiveness to consumers of efficiency technologies relative to current baseline.

- Impacts on the current market from efficiency regulations.

- National energy and financial impacts.

The analysis relied on detailed and up-to-date technical data made available by BEE and industry representatives. Technical parameters were used in conjunction with knowledge about air conditioner use patterns in the residential and commercial sectors, and prevailing marginal electricity prices, in order to give an estimate of per-unit financial impacts. In addition, the overall impact of the program was evaluated by combining unit savings with market forecasts in order to yield national impacts. LBNL presented preliminary results of these analyses in May 2006, at a meeting of BEEs Technical Committee for Air Conditioners. This meeting was attended by a wide array of stakeholder, including industry representatives, engineers and consumer advocates. Comments made by stakeholders at this meeting are incorporated into the final analysis presented in this report.

The current analysis begins with the Rating Plan drafted by BEE in 2006, along with an evaluation of the market baseline according to test data submitted by manufacturers. MEPS, label rating levels, and baseline efficiencies are presented in Section 2. First, we compare Indian MEPS with current standards in other countries, and assess their relative stringency. Baseline efficiencies are then used to estimate the fraction of models likely to 
remain on the market at each phase of the program, and the impact on market-weighted efficiency levels.

Section 3 deals with cost-effectiveness of higher efficiency design options. The cost-benefit analysis is grounded in technical parameters provided by industry representatives in India. This data allows for an assessment of financial costs and benefits to consumers as a result of the standards and labeling program. A Life-Cycle Cost (LCC) calculation is used to evaluate the impacts of the program at the unit level, thus providing some insight into the appropriateness of the levels chosen, and additional opportunities for further ratcheting. In addition to LCC, we also calculate payback periods, cost of conserved energy (CCE), and return on investment (ROI).

Finally, Section 4 covers national impacts. This is an extension of unit level estimates in the two previous sections. Extrapolation to the national level depends on a forecast of air conditioner purchases (shipments), which we describe here. Following the cost-benefit analysis, we construct several efficiency scenarios including the BEE plan, but also considering further potential for efficiency improvement. These are combined with shipments through a stock accounting model in order to forecast air conditioner energy consumption in each scenario, and associated electricity savings and carbon emission mitigation. Finally, financial costs and savings are scaled to the national level to evaluate net fiscal benefits.

\section{BEE Draft Standards}

India's Bureau of Energy Efficiency (BEE) is uniquely charged with developing programs for minimum efficiency performance standards (MEPS) and comparative labeling for energy consuming equipment sold in the country. BEE announced the unveiling of their first set of standards, for refrigerators, in May of 2006. BEE chose to implement a combination of MEPS and mandatory labels based on a star system at the same time. In addition, rather than issuing one set of parameters, they chose to announce several phases, with successively more rigorous requirements taking effect after a period of several years. The announcement of refrigerator standards was followed in the same year by an announcement for standards affecting room air conditioners. Air conditioner standards follow the same structure as those for refrigerators.

BEE's published document announcing the first set of efficiency standards for appliances and other energy-consuming equipment described the philosophy of review and update in the following way:

"Instead of setting a very tough standard and rating plan at the onset of the program, a phased approach is being adopted, wherein the rating plan will be upgraded every two years till an internationally benchmarked energy efficiency level is achieved."

Subsequent determination of rating levels for air conditioners is guided by the same principle, with a goal to "achieve highest international benchmark within a span of 4-6 years." The ratings effective January 1, 2007, and subsequent updates in 2008 and 2010 are shown in Table 1.

The lowest allowable rating is the one star level. Models not meeting the minimum Energy Efficiency Rating (EER) for this level will be prohibited for sale on the market. The ratings system does not distinguish between window and split units. The rating system follows a 
straightforward scheme. The minimum is set by the one star level, and models are awarded an additional star for each increment of 0.2 EER (W/W) by which they surpass the minimum. The range from one to five stars therefore spans 0.9 units of EER. This is a sizable range, and as we will see below, removes quite a few models at the low end, and far surpasses the best models at the high end.

Table 1 BEE Rating Scheme for Room Air Conditioners (Window and Split).

\begin{tabular}{|c|c|c|c|c|c|c|}
\hline & \multicolumn{6}{|c|}{ Minimum EER } \\
\hline $\begin{array}{l}\text { Implementation } \\
\text { Date }\end{array}$ & \multicolumn{2}{|c|}{1 Jan 2007} & \multicolumn{2}{|c|}{1 Jan 2008} & \multicolumn{2}{|c|}{1 Jan 2010} \\
\hline Star Rating & W/W & Btu/hr/W & W/W & Btu/hr/W & W/W & Btu/hr/W \\
\hline * & 2.3 & 7.8 & 2.5 & 8.5 & 2.7 & 9.2 \\
\hline ** & 2.5 & 8.5 & 2.7 & 9.2 & 2.9 & 9.9 \\
\hline$\star \star \star *$ & 2.7 & 9.2 & 2.9 & 9.9 & 3.1 & 10.6 \\
\hline 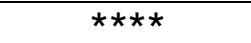 & 2.9 & 9.9 & 3.1 & 10.6 & 3.3 & 11.3 \\
\hline$\star \star \star \star \star \star$ & 3.1 & 10.6 & 3.3 & 11.3 & 3.5 & 11.9 \\
\hline
\end{tabular}

The gradual tightening of standards is also straightforward, and follows the example set by BEE for refrigerator standards. At each step, the one star units are removed from the market, and the old two star models are demoted to one star, three star models become two stars, etc. By 2010, the minimum level is set at the three star level of 2007.

\subsection{Comparison with International Levels}

Comparison of air conditioner regulations across countries is not straightforward, because ratings are generally defined by cooling capacity ranges, which vary from one country to another. Furthermore, most countries define different standards for window and split units, while the Indian levels apply for both product classes. Finally, in North America, product classes for window units are subdivided according to other features, such as the presence of louvered sides or availability of a reverse cycle.

In order to make some comparison, we consider the levels that apply to what we consider a typical Indian air conditioner - a 1.5 ton $(5275 \mathrm{~W})$ cooling capacity window unit with louvered sides. The minimum performance levels defined by BEE are shown in Figure 1, compared with MEPS defined in China, Korea, and North America (North America includes the United States, Canada and Mexico).

United States was an early adopter of MEPS, with standards for window-type room air conditioners coming into force in 1990. A second, much more stringent set of requirements came into effect in 2000. Mexico's first set of MEPS came into force in 1995, and included room air conditioners. Since that time, Mexican standards have been updated several times towards harmonization with U.S. regulations. By now, standards in the U.S., Mexico and Canada are fully harmonized. Even though there was some lag time in Mexican and Canadian MEPS relative to those of the U.S., we show the levels of all three countries with a single series. The North American countries define 16 separate product classes, with levels dependent on cooling capacity, intended window installation (i.e., typical doublehung, casement only, or casement slider), presence of louvered sides, and availability of a reverse cycle. For window units with 1.5 ton cooling capacity, with non-louvered sides, and 
no reverse cycle, MEPS were set at $2.58 \mathrm{EER}(8.8 \mathrm{kBtu} / \mathrm{kWh})$ in 1990 , and raised to 2.84 EER $(9.7 \mathrm{kBtu} / \mathrm{kWh})$ in 2000 . These standards are among the most stringent in the world for air conditioners. ${ }^{1}$

\section{Figure 1 - MEPS for 1.5 ton Window Air Conditioners - 1994-2010}

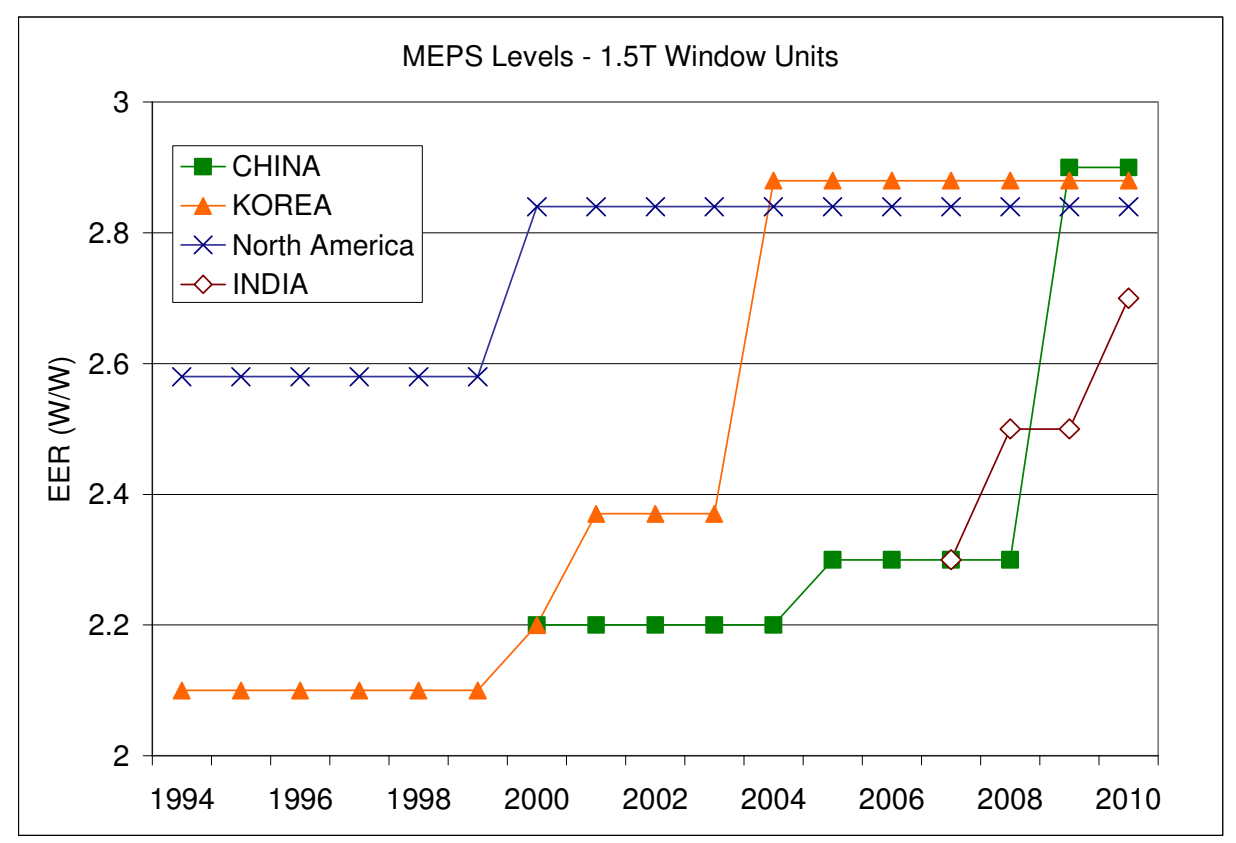

Both China and the Republic of Korea have introduced appliance MEPS that include window air conditioners. Standards in these countries, started out quite low, but were successively tightened to a level comparable with North American standards. Korea set standards in 1994, and upgraded them three times. The standard which came into effect in 2003 brought the level of efficiency of air conditioners to 2.88, making them the most stringent MEPS in the world for this product class. Chinese standards were at one time comparable with those of Korea. In fact, in 2000, the two were equal. By now, however, China lags behind, with even the 2005 standard being much lower than the Korean 2003 standard. This situation will change, however, in 2009, as China has already announced 'reach' standards which will actually exceed the current Korean MEPS. If no upgrades are made in the next few years, these Chinese standards will probably be the world's most stringent.

Comparing the BEE standards in this way reveals a couple of interesting features. First of all, the trend of the other countries implies a convergence of international best practice at

\footnotetext{
${ }^{1}$ Under North American country regulations, mini-split air conditioners are not considered under the same set of requirements as window units, rather, they are regulated according to standards set for central air conditioning. The current minimum efficiency rating for mini-splits in the U.S. is therefore 13 SEER (Seasonal EER). SEER represents the amount of cooling performed during a cooling season (in Btu) divided by the energy input required to perform that cooling (in Watt-hr). The metric equivalent to 13 SEER is 3.8 $\mathrm{W}$-hr/W-hr, For single-speed units, SEER is determined by evaluating the performance at four test conditions - three more than what are needed to determine EER. Thus SEER and EER cannot be directly compared. But as a rough approximation for single-speed units, $3.8 \mathrm{~W}$-hr/W-hr corresponds to about 3.4 EER. This high standard actually impacts relatively few units, however, since mini-splits are rare in the United States.
} 
about 2.9 EER. There is a large gap between current Chinese standards and the proposed Indian Standard level, a gap that the Korean program has already crossed. When the Indian standards come on line this year, they will already be in-line with those in China, so India will have caught up with one of the major players (and of course, a major competitor in the market). This parity won't last long however, as Chinese standards will jump again in 2009. BEE already prescribes two updates in rapid succession, however. In fact, one can view the BEE target in terms of a stringent 2010 standard with a 3-year ramp up. By the end of this period, efficiency in India will not quite catch up, but will have closed most of the gap, and will have done so much more rapidly than other countries did at the start of their programs. Of course, the MEPS level defines only the poorest performing units allowed on the market. These comparisons therefore, do not precisely describe the average efficiency of the market in each country. In particular, it does not take into account the impact of the Indian labeling program, or labeling programs in other countries.

Although Indian standards for window units will approach international levels by 2010, it is important to note that these standards significantly lag behind international levels for split units. Split unit standards in China, Korea, Japan, and the U.S. either already exceed or will exceed 3.1 EER by 2009. Because the Indian air conditioner market is likely to transition away from window to split units, Indian standards must continue to increase their standards in order to keep pace with international levels. ${ }^{2}$

\subsection{Current Market and Impact of Standards}

As part of the process of determination of the rating plan for air conditioners, BEE conducted a baseline study to establish the current efficiency levels of air conditioners on the market. Collection of these data allows for more accurate evaluation of the rating plans and assessment of program impacts. BEE plans to repeat the study each year in order to monitor the program impact.

As part of the study, a total of 15 air conditioners of 1.5 ton $(18,000 \mathrm{Btu} / \mathrm{hr}$ or $5275 \mathrm{~W})$ cooling capacity were selected based on the market share of each model. Of these, data from 11 models were available for this study. The 1.5 ton capacity category is the most common in India. A recent study by BEE (IMRB 2004) estimated that $78 \%$ of the window units on the market were rated at 1.5 tons.

The model samples, comprised of both window and split units, were provided by the manufacturers, who assured that the models were regular production models, and not prototypes. The tests were conducted at Intertek's test facility in Delhi, which is a facility accredited by the Indian national accreditation agency NABL. The results of these tests are shown in Table 2.

\footnotetext{
${ }^{2}$ Comments from industry representatives in India indicate that the mini-split product class is gaining market share.
} 
Table 2 Tested Energy Efficiencies of the Most Popular 1.5 Ton ACs in India in 2006

\begin{tabular}{|c|c|c|c|c|c|c|}
\hline \multirow{2}{*}{ № } & \multirow{2}{*}{ Type } & \multicolumn{3}{|c|}{ Capacity } & \multicolumn{2}{c|}{ EER } \\
\cline { 3 - 7 } & & W & Btu/hr & Tons & W/W & Btu/hr/W \\
\hline 1 & Split & 5074 & 17312 & 1.44 & 2.60 & 8.86 \\
\hline 2 & Split & 4552 & 15532 & 1.29 & 2.28 & 7.78 \\
\hline 3 & Window & 4438 & 15144 & 1.26 & 2.17 & 7.42 \\
\hline 4 & Split & 4786 & 16332 & 1.36 & 2.45 & 8.35 \\
\hline 5 & Window & 4809 & 16410 & 1.37 & 2.54 & 8.67 \\
\hline 6 & Window & 4786 & 16332 & 1.36 & 2.35 & 8.03 \\
\hline 7 & Split & 5054 & 17244 & 1.44 & 2.67 & 9.1 \\
\hline 8 & Window & 4367 & 14901 & 1.24 & 2.14 & 7.3 \\
\hline 9 & Split & 4037 & 13776 & 1.15 & 2.01 & 6.84 \\
\hline 10 & Window & 4267 & 14558 & 1.21 & 2.25 & 7.69 \\
\hline 11 & Split & 4826 & 16466 & 1.37 & 2.48 & 8.49 \\
\hline
\end{tabular}

Five of the 11 units shown in the table were found to have an efficiency rating level of less than 2.3, which is the minimum allowable rating as of January 2007. This implies that nearly half of the models sold in India, in market share terms, will be eliminated by the first set of standards. The distribution of model efficiency and the correspondence to the standards is shown in Figure 2. In this figure, efficiency level is plotted vs. capacity. There is a clear linear relationship between the two parameters, with the largest models being rated the most efficient. The figure shows the initial 2007 rating plan, and the second revision in 2010. The intermediary plan, which comes into effect in 2008 is not shown, but is easily inferred from the other two.

Figure 2 - Air Conditioner Test Data and Rating Plan - 2007-2012

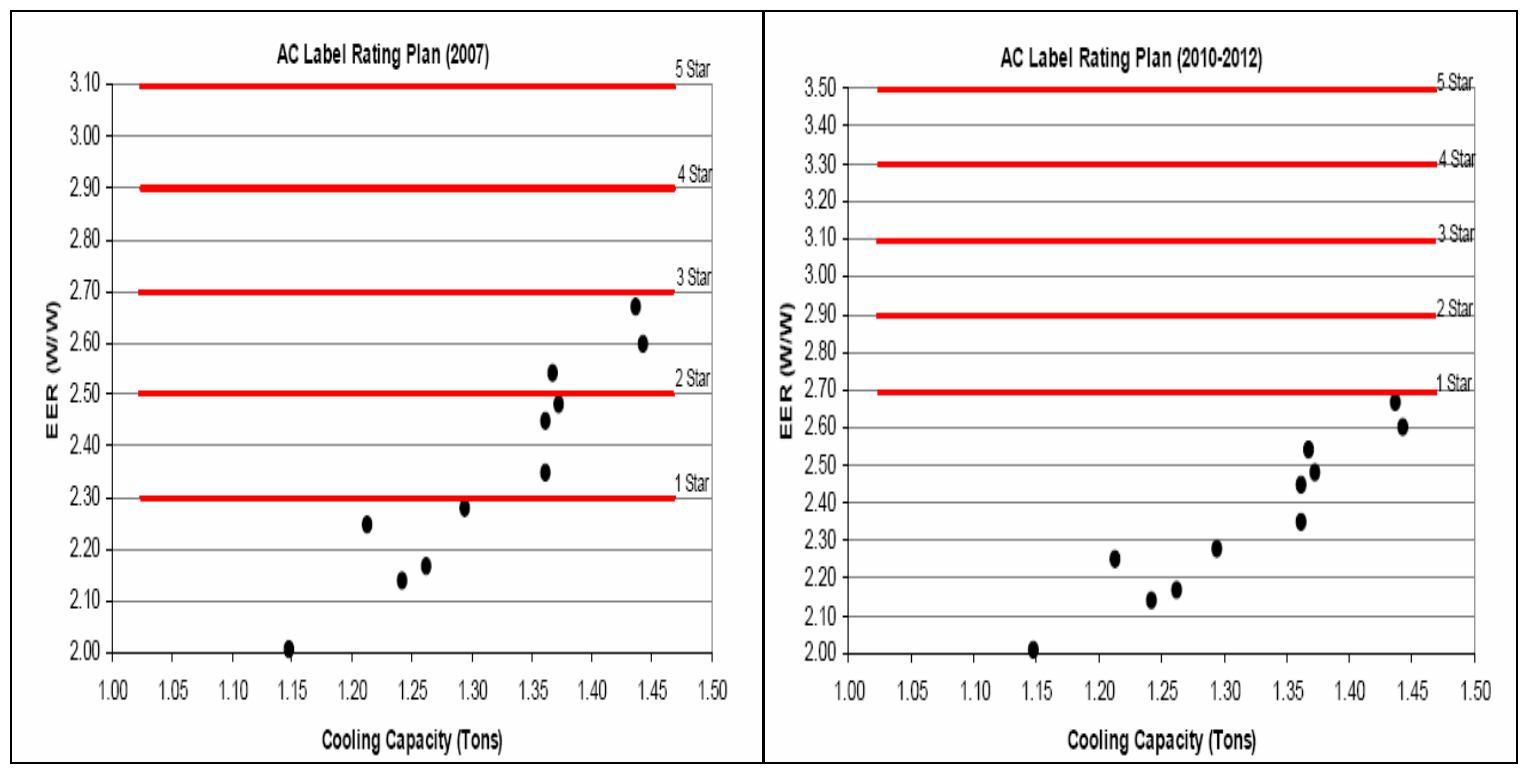

By January 2007, only 6 of the 11 models tested will be permitted for sale. Of these, 3 will be rated one star, and three will be rated with two stars. Since the 2008 plan is a ratcheting of one star level, only 3 of the current sample would be allowed at that time, and would be 
rated one star only. Finally, if the 2010 plan were implemented today, none of the models would pass the MEPS.

If the models tested are representative of the market as a whole, therefore, the MEPS and ratings plan are quite stringent. This is especially evident by the fact that with three years lead time (by 2010) Indian manufacturers will have to improve their entire line of products. In the meantime, the current production line will be rated with only one or two stars. The program as designed therefore maximizes manufacturers' obligation and incentive for improving the efficiency of their products as much as possible.

Energy savings in the air conditioning market due to an efficiency program depends on the response of the market as a whole. This behavior is impossible to predict with certainty, but conclusions drawn from the current distribution of products is indicative, if not precise. In this section, we evaluate the impact of market transformation which can be attributed to MEPS only. We define this quantitatively as the impact on the market of improving lowefficiency units just to the minimum level and no further. This is a convenient definition, but it is not meant to represent a realistic scenario. In all likelihood, imposition of MEPS will lead to improvement beyond the minimum as manufacturers try to remain competitive. In addition, the labeling component will have in impact that is difficult to separate from the impact of MEPS. In section 4 where national energy impacts are discussed, we construct a more realistic MEPS+Labels scenario, which captures the full likely impacts of the program.

The MEPS only effect will be significant in itself, since a large portion of the models will already be eliminated by 2007, and none would pass the 2010 standard. In order to estimate the impact of MEPS, we make the simple assumption that every model which is removed from the market will be replaced by one which barely passes it. This corresponds to the conservative assumption that manufacturers will do the bare minimum to get existing models up to the level of compliance. For those models which already pass the standard, we assume no improvement. The results of these assumptions are shown in Table 3.

Table 3 Estimated Market-wide Impacts of MEPS Only

\begin{tabular}{|c|c|c|c|c|c|}
\hline & \multicolumn{2}{|c|}{$\begin{array}{c}\text { Models } \\
\text { Passing }\end{array}$} & \multicolumn{3}{c|}{ Efficiency (EER) } \\
\hline & No. & $\%$ & MEPS & Average & $\begin{array}{c}\% \\
\text { Imp. }\end{array}$ \\
\hline Baseline & 11 & $100 \%$ & & 2.36 & \\
\hline 2007 & 6 & $55 \%$ & 2.30 & 2.42 & $2 \%$ \\
\hline $2008-2009$ & 3 & $27 \%$ & 2.50 & 2.53 & $7 \%$ \\
\hline 2010 & 0 & $0 \%$ & 2.70 & 2.70 & $13 \%$ \\
\hline
\end{tabular}

The table shows the numbers of models in the testing sample which would pass each successive MEPS. The market weighted efficiency is the simple average of all 11 models given the assumptions above. The MEPS in 2007 shows the smallest level of improvement, because many of the models will already pass the standard, and we assume these do not change. The market level after January 2008 is just above the minimum of 2.5 EER. Finally, by 2010, there is a completely new market of products that just pass the standard of 2.7. By this time, just meeting the minimum requirements of the MEPS will have improved the overall market efficiency by $13 \%$. 
The transformation of the market is likely to be greater than that suggested by Table 3 , for two reasons. First, manufactures implementing efficiency technologies may find that it is cost-effective and in their interest to go beyond the minimum required by the standards. More important, however, is the impact of the labeling program. The conservative estimate assumes only a small number of models at two stars in 2007 and no models beyond two stars. After 2008, all models will be rated with one star. The goal of the labeling program, however, is precisely to encourage manufacturers to market a significant number of models at the three or four star level. The efficiency improvement due to a successful labeling program is considered below in Section 4 as part of the construction of efficiency scenarios.

\section{Cost Effectiveness}

It is important to evaluate the cost effectiveness of efficiency measures for both labeling and standards programs, particularly if these are mandatory, as they are in India. In general, an analysis of equipment cost increases and operating cost savings serves three functions:

- It informs manufacturers of the potential per-unit cost increases they may face in order to meet the rating requirements.

- It informs the implementing agency of the benefits of the program at the consumer level.

- It can be scaled to the level of the market as a whole, allowing for assessment of national financial benefits.

In the case of a labeling program, energy efficiency becomes a marketing tool as an attractive selling point to consumers. The attractiveness of buying energy efficient equipment may be offset somewhat, however, by higher retail prices on these models. A detailed analysis of likely costs to achieve efficiency targets therefore gives manufacturers the ability to optimize the trade-offs between highly rated products, and higher retail prices. In the case of MEPS, cost-benefit analysis is even more critical, since in this case the regulation imposes real costs on the consumer, and generally implementing agencies are reluctant to impose onerous costs. On the other hand, MEPS can generally be engineered such that they provide a net benefit to consumers, and a cost-benefit analysis allows for design of regulations that maximize financial benefits, or maximize energy savings to the nation. In this section, we evaluate the cost-effectiveness of a variety of efficiency design options from the consumer viewpoint, and compare them to the MEPS levels set by BEE. In addition, the cost-benefit analysis gives some indication of gains likely to be made by the labeling component, and the construction of alternative efficiency scenarios.

There are several alternative methodologies to characterize cost-effectiveness. These include:

- Life Cycle Cost - LCC calculates the net incremental cost over the life of the appliance, including increased equipment (first) cost, and lifetime operation cost savings, which are discounted according to the year from purchase they are accrued.

- Payback Period - The number of years after which cumulative operating cost savings exceed incremental equipment cost. 
- Cost of Conserved Energy - The incremental first cost paid divided by discounted energy savings over the life of the appliance. Cost effectiveness is evaluated by comparing the $\mathrm{CCE}$ with prevailing electricity prices.

- Return on Investment - The average rate of return over the life of the appliance. This evaluation allows for comparison of the investment into efficiency with other interestyielding investment alternatives.

\subsection{Cost Efficiency Relationship}

In order to estimate cost effectiveness, the relationship between equipment prices and efficiency must be known. The most reliable way to generate a price-efficiency curve is by considering specific design options known to increase efficiency by certain amount, and their associated costs. The cost of efficiency can be estimated in terms of material costs to manufacturers, which can then be scaled by the appropriate markups in order to estimate retail prices. It is difficult to estimate the relationship between efficiency and retail price directly, because pricing policies of manufacturers and retailers are unknown, and prices are determined by many factors other than efficiency. The assumption that markups are constant across products, gives a reasonable estimate, however ${ }^{3}$.

The cost-benefit analysis relies heavily on engineering parameters provided by Indian manufacturer representatives. This data was provided to BEE, and shared with LBNL researchers as part of the development of a techno-economic analysis, which was presented to the Air Conditioner Technical Committee in May of 2006. Table 4 shows the raw data as provided. Data were provided only for window units. We assume that incremental retail prices, and the cost-efficiency relationship given for window units also holds for split systems. This assumption is a rough approximation which may not reflect the actual costefficiency relationship for split units. As noted earlier in section 2.1, although window units currently account for about $60 \%$ of the Indian room AC market ${ }^{4}$, the market is quickly transitioning to split units. As a result, costs for window units, which may be reflective of split unit costs today, may no longer be representative of split unit costs in the future as manufacturers put more of their attention on the design and production of split units. Thus, although the efficiency options being considered for window units are similar to what would be applied to split units, their cost implications for split units could significantly change due to manufacturing efficiencies gained by increasing split unit product volumes.

First, the data specify the typical configuration of units currently on the market, that is, the baseline design (Design Option 0). The baseline efficiency is estimated to be around 2.3 EER. As discussed in the previous section, about half of the units tested perform better than this level, and half are below. Each successive design option added to the baseline

\footnotetext{
${ }^{3}$ In some sense, this assumption can be seen as a conservative one, for two reasons. First, fractional increases in material cost will generally not impose an equivalent fractional total production cost, since labor costs may not increase significantly. Secondly, manufacturers facing efficiency regulations typically have found ways to achieve lower than estimated costs, through economies of scale, and increased efficiency of production methods.

${ }^{4}$ Source: RAMA
} 
configuration has the effect of raising the efficiency. In addition, inclusion of these features increases manufacturer costs for materials, labor, and retooling. These additional costs are reflected in higher estimated retail price. Retail prices are given in rupees, and also converted to U.S. dollars according to an average exchange rate for 2006 of 45.19 Rs. $/ \$^{5}$. Table 4 gives an indication of the price increases likely to face consumers as a result of MEPS. The MEPS of 2.3 is very close to the level of the baseline, therefore, consumers will likely see little price impact. The 2008 MEPS falls between design option 1 and two, so we would expect a retail price of between 17535 Rs. and 18135 Rs. (\$388 and \$401), or an increase of between Rs.1035 and Rs. 1635 (\$23 and \$36). Finally, the 2010 MEPS implies a retail price of Rs. 18735 (\$415), or an increase of Rs. 2235 (\$50).

Table 4 Cost-Efficiency Relationship for Indian Window Air Conditioners

\begin{tabular}{|c|l|c|c|c|c|}
\hline \multicolumn{2}{|c|}{ Design Options } & \multicolumn{2}{c|}{ Retail Price } & \multicolumn{2}{c|}{ EER } \\
\cline { 3 - 6 } & $($ Rs. $)$ & $(\$)$ & W/W & Btu/h/W \\
\hline $\begin{array}{c}0 \\
\text { Baseline }\end{array}$ & $\begin{array}{l}10 \text { EER Comp. + 7mm Coil Diameter + Grooved } \\
\text { Tubes }\end{array}$ & 16500 & $\$ 365$ & 2.29 & 7.8 \\
\hline 1 & $\begin{array}{l}0+\text { Increased Heat Exchanger + 9.5mm Evap. } \\
\text { Diameter + 50\% increase in Evap. Surface Area }\end{array}$ & 17535 & $\$ 388$ & 2.42 & 8.3 \\
\hline 2 & $1+$ Incr Compressor EER to 10.8 & 18135 & $\$ 401$ & 2.64 & 9.0 \\
\hline 3 & $2+$ Add Subcooler & 18735 & $\$ 415$ & 2.70 & 9.2 \\
\hline 4 & $4+$ Increase Cond Coil Area by 50\% & 19735 & $\$ 437$ & 2.81 & 9.6 \\
\hline 5 & $5+$ BPM Fan Motor & 24235 & $\$ 536$ & 2.93 & 10.0 \\
\hline 6 & $8+{ }^{*}$ Variable Speed Compressor & 32535 & $\$ 720$ & 3.28 & 11.2 \\
\hline
\end{tabular}

* 2 row +2 row L Shape Condenser

** Efficiency gains shown for variable speed compressors reflect the energy savings that are achievable from the design through improvements in part-load and cyclic performance. Variable speed compressors do not show measurable improvements in EER based on current test procedures.

\subsection{Consumer Financial Impacts}

Given that higher efficiency products cost more, the cost-benefit to consumers will depend on whether the investment into higher first costs is adequately compensated by lower electricity bills. Electricity bill savings are in turn dependent on the hours of use of the product, and unit electricity prices. Both of these parameters depend on whether the air conditioner is used in a commercial setting, such as a shop or office building, or whether it is used in a private residence.

Traditionally, commercial firms have been the dominant purchasers of air conditioners in India, but this situation is changing. In 2002-2003, RAMA estimates that half of the air conditioners sold in India were purchased for use in homes, and this fraction rose gradually to $58 \%$ by 2006 . Because of the significant difference in use patterns and electricity rates between commercial and residential users, we evaluate cost effectiveness separately for each user type. The parameters considered separately are unit energy consumption (UEC), marginal electricity rates, and discount rates.

\footnotetext{
${ }^{5}$ Exchange rate from http://international.neded.org/exchrate.htm, last accessed February 9, 2007.
} 


\section{Unit Energy Consumption}

Unit Energy Consumption (UEC) is calculated by estimating the number of hours per day and per month that the business or household operates each air conditioner. Investigations by RAMA indicate the following use patterns:

- Commercial Use -9 months/yr $\times 25$ days/month $\times 8$ hours/day $=1800$ hours/yr.

- Residential Use -6 months/yr $\times 30$ days/month $\times 8$ hours/day $=1440$ hours/yr

The hours of use can be combined with the power consumption of a typical air conditioner in order to arrive at energy consumption. The capacity rating of air conditioners is based on being operated at full power. We assume that the consumer operates the air conditioner at $75 \%$ of full capacity on average, and apply a scaling factor of 0.75 . A $1.5 \mathrm{~T}$ unit typically operates at $2 \mathrm{~kW}$ full power ${ }^{6}$. Therefore, UEC is given by

$$
2 \mathrm{~kW} \times 0.75 \times \text { Hours, }
$$

which yields $2700 \mathrm{kWh}$ per year for commercial users, and $2160 \mathrm{kWh}$ per year for residential users.

\section{Marginal Electricity Prices}

Residential electricity rates are much lower than commercial rates in India. Residential electricity rates are subsidized to a large degree (but to a much lesser degree than agricultural rates), and consumers pay low rates on average. Rates collected by most State Electricity Boards in India, however, have a residential tariff schedule that charges significantly higher rates for usage above a certain baseline. The impact of higher electricity efficiency will be to reduce consumption in the highest block. Therefore, the relevant consumer electricity savings is calculated according to this marginal price. Marginal prices were calculated by LBNL for a previous study using SEB tariff rates that covered most of India, and found to be 2.70 Rs. per kWh (LBNL 2005), or about $\$ 0.059 / \mathrm{kWh}$. That report reported the average cost of production to be $3.50 \mathrm{Rs}$. per $\mathrm{kWh}$, or $\$ 0.077 / \mathrm{kWh}^{7}$, so even at the margin, residential electricity bills do not cover utility costs. In contrast, the study found that marginal electricity rates for commercial customers exceeded the cost of production significantly at $4.80 \mathrm{Rs}$. per $\mathrm{kWh}$. As we show below, this difference has major impacts on the cost-effectiveness of various designs on different consumers.

It should be noted that reform of electricity tariff structures is a long standing issue. A discussion of this issue and a projection of likely future trends in marginal electricity is beyond the scope of this report. It seems safe to say, however, that residential rates are likely to rise in the next decade or so. Nevertheless, we use current rates to evaluate cost effectiveness, which is in some way a conservative assumption.

\footnotetext{
${ }^{6}$ A $2000 \mathrm{~W}$ unit with baseline EER of 2.29 has a cooling capacity of $4580 \mathrm{~W} / \mathrm{h}$, which is typical of the tested sample of $1.5 \mathrm{~T}$ units.

${ }^{7}$ From Planning Commission Annual Report on State Electricity Boards and Electricity Departments 20022003
} 


\section{Discount Rates}

Consumers value immediate savings more than future savings. The time value of money is typically accounted for by discounting future savings using a discount rate. There is limited data on which to base consumer discount rates in India. The rate currently used by utilities for their investment in demand-side efficiency programs is $10 \%$. We assume that rates used for other sectors will be somewhat higher, with residential consumers discounting deferred savings by the largest factor. We therefore assume a discount rate of $15 \%$ for residential consumers, and a slightly lower rate of $12 \%$ for commercial consumers.

Given estimates of retail price, UEC, and electricity prices, calculation of cost-benefit estimators is straightforward. The first of these is a Life Cycle Cost (LCC) calculation. $\mathrm{LCC}$ is given by

$$
L C C=P+\sum_{n=1}^{L} \frac{O C}{(1+D R)^{n}}
$$

In this equation, $P$ is the air conditioner retail purchase price, $O C$ is the annual operating cost (air conditioning utility bill), and $D R$ is the discount rate. The sum runs over the life of the appliance, which we assume to be 15 years. Life Cycle Cost is given for both consumer types in Table 5 and Table 6.

Table 5 Cost-Effectiveness of Energy Efficiency - Commercial Customers

\begin{tabular}{|c|c|c|c|c|c|c|c|c|c|c|c|}
\hline \multirow{3}{*}{$\begin{array}{l}\text { Design } \\
\text { Option }\end{array}$} & \multicolumn{2}{|c|}{ Retail Price } & \multirow[b]{2}{*}{ EER } & \multirow[b]{2}{*}{ Energy } & \multicolumn{2}{|c|}{ Operating Cost } & \multicolumn{2}{|c|}{ Life Cycle Cost } & \multirow[b]{2}{*}{ Payback } & \multirow[b]{2}{*}{ CCE } & \multirow[b]{2}{*}{$\mathrm{ROI}$} \\
\hline & Price & $\Delta$ Price & & & $\mathrm{OC}$ & $\Delta \mathrm{OC}$ & LCC & $\Delta \mathrm{LCC}$ & & & \\
\hline & Rs. & Rs. & kBtu/kWh & $k W h$ & Rs. & Rs. & Rs. & Rs. & Years & Rs. & $\%$ \\
\hline 0 & 16,500 & 0 & 2.29 & 2700 & 13,001 & 0 & 105,049 & 0 & & & \\
\hline 1 & 17,535 & 1,035 & 2.4 & 2547 & 12,265 & -736 & 101,072 & $-3,977$ & 1.4 & 0.994 & $71 \%$ \\
\hline 2 & 18,135 & 1,635 & 2.6 & 2340 & 11,268 & $-1,733$ & 94,877 & $-10,172$ & 0.9 & 0.667 & $106 \%$ \\
\hline 3 & 18,735 & 2,235 & 2.7 & 2289 & 11,023 & $-1,978$ & 93,809 & $-11,240$ & 1.1 & 0.799 & $89 \%$ \\
\hline 4 & 19,735 & 3,235 & 2.8 & 2194 & 10,563 & $-2,438$ & 91,681 & $-13,368$ & 1.3 & 0.938 & $75 \%$ \\
\hline 5 & 24,235 & 7,735 & 2.9 & 2106 & 10,141 & $-2,860$ & 93,303 & $-11,746$ & 2.7 & 1.912 & $37 \%$ \\
\hline 6 & 32,535 & 16,035 & 3.3 & 1880 & 9,054 & $-3,947$ & 94,203 & $-10,846$ & 4.1 & 2.872 & $24 \%$ \\
\hline
\end{tabular}

Discount Rate 12\%, Electricity Price 4.8 Rs. / kWh, Lifetime 15 yr.

Table 6 Cost-Effectiveness of Energy Efficiency - Residential Customers

\begin{tabular}{|c|c|c|c|c|c|c|c|c|c|c|c|}
\hline \multirow{3}{*}{$\begin{array}{l}\text { Design } \\
\text { Option }\end{array}$} & \multicolumn{2}{|c|}{ Retail Price } & \multirow[b]{2}{*}{ EER } & \multirow[b]{2}{*}{ Energy } & \multicolumn{2}{|c|}{ Operating Cost } & \multicolumn{2}{|c|}{ Life Cycle Cost } & \multirow[b]{2}{*}{ Payback } & \multirow[b]{2}{*}{ CCE } & \multirow[b]{2}{*}{$\mathrm{ROI}$} \\
\hline & Price & $\Delta$ Price & & & OC & $\Delta \mathrm{OC}$ & LCC & $\Delta \mathrm{LCC}$ & & & \\
\hline & Rs. & Rs. & kBtu/kWh & $k W h$ & Rs. & Rs. & Rs. & Rs. & Years & Rs. & $\%$ \\
\hline 0 & 16,500 & 0 & 2.3 & 2160 & 5,788 & 0 & 50,343 & 0 & & & \\
\hline 1 & 17,535 & 1,035 & 2.4 & 2038 & 5,460 & -328 & 49,463 & -881 & 3.2 & 1.448 & $31 \%$ \\
\hline 2 & 18,135 & 1,635 & 2.6 & 1872 & 5,016 & -772 & 47,466 & $-2,877$ & 2.1 & 0.971 & $47 \%$ \\
\hline 3 & 18,735 & 2,235 & 2.7 & 1831 & 4,907 & -881 & 47,428 & $-2,915$ & 2.5 & 1.163 & $39 \%$ \\
\hline 4 & 19,735 & 3,235 & 2.8 & 1755 & 4,703 & $-1,085$ & 47,233 & $-3,111$ & 3.0 & 1.366 & $33 \%$ \\
\hline 5 & 24,235 & 7,735 & 2.9 & 1685 & 4,514 & $-1,273$ & 50,633 & 289 & 6.1 & 2.784 & $14 \%$ \\
\hline 6 & 32,535 & 16,035 & 3.3 & 1504 & 4,031 & $-1,757$ & 56,105 & 5,761 & 9.1 & 4.182 & $7 \%$ \\
\hline
\end{tabular}

Discount Rate $12 \%$ Electricity Price 2.7 Rs. / kWh, Lifetime 15 yr.

Life Cycle Cost is about twice as high for commercial customers because of the higher electricity rates, higher hours of operation, and a lower discount rate. The lifetime costs for 
these consumers is about Rs. 105,000, or about $\$ 2,300$. First cost only accounts for a sixth of LCC for these users, while it's about a third of residential user LCC. Design option 4 gives the minimum LCC for both consumer categories, and therefore is the most costeffective option according to this metric. Using a 2.8 EER product instead of a 2.3 EER model saves commercial consumers Rs. 13,368 and residential consumers Rs. 3,111, or about $\$ 300$ and $\$ 70$ respectively. It is important to note that in the commercial user case, LCC of design options 5 and 6 (2.9 and 3.3 EER) are also cost-effective and thus provide savings over the life of the appliance. This is not true, however, in the residential case, where the high price of these models would cause LCC to exceed that of the base case, although at the 2.9 EER level the difference is somewhat marginal.

The results of the LCC analysis are shown graphically in Figure 3. The minimum LCC for both consumer types occurs at 2.8 EER. This is slightly beyond the MEPS which will come into effect on January 1, 2010. This implies that the baseline unit at that time will be nearly optimal to all consumers and that manufacturers will have some room to spare to produce units of even higher efficiency which will still provide a net benefit to consumers. In addition, by that time, manufacturers may have found a way to lower costs associated with efficiency (e.g. through economies of scale) and/or will be able to successfully market higher priced products as a result of the labeling program.

\section{Figure 3 Life Cycle Cost of Window AC Design Options}

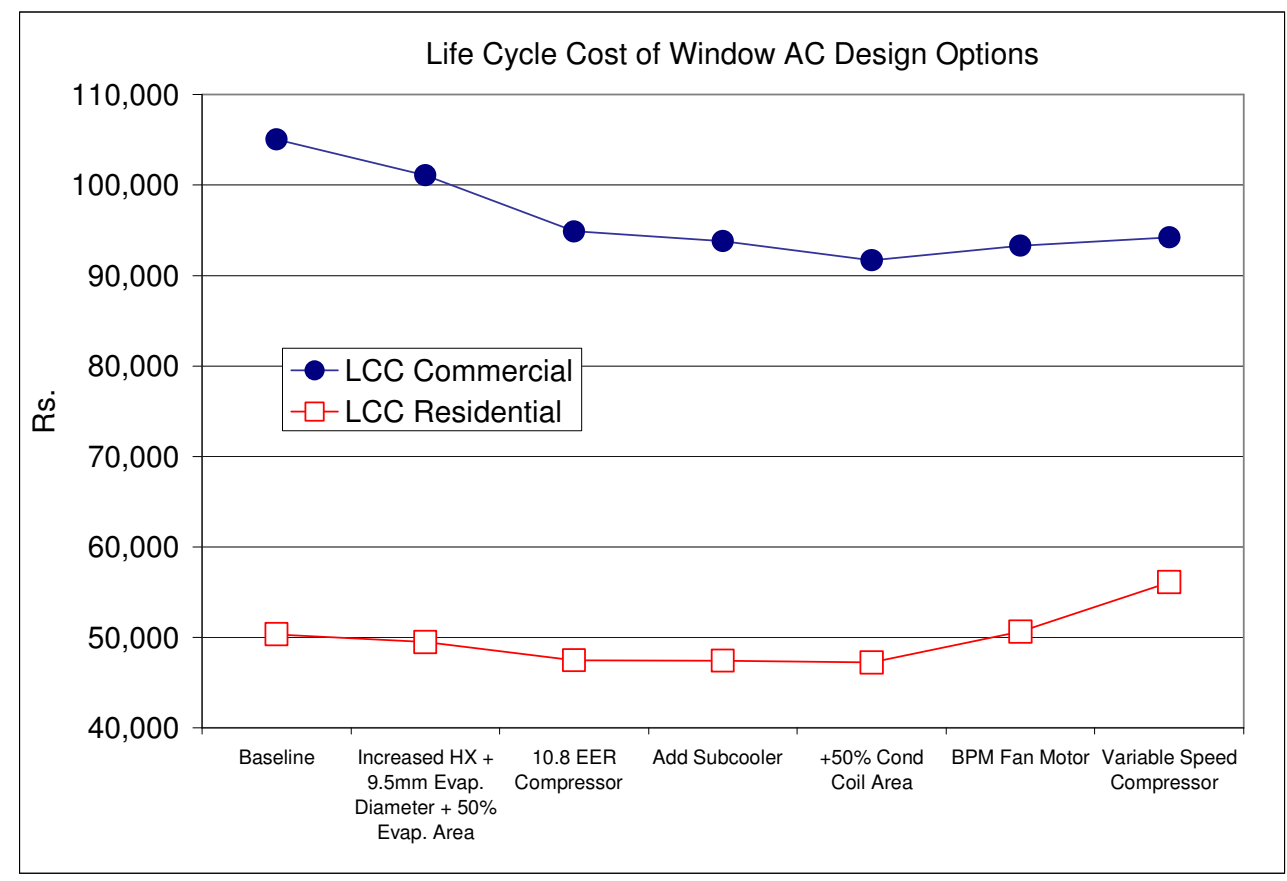

The calculation of simple payback yields similar results to the LCC analysis. Payback is almost always less than 3 years for commercial consumers. For residential consumers, payback is between 2.1 and 3.2 years for the first four design options. For the most efficient two options, it is 6 years and 9 years. The discount rate for consumers used in the LCC analysis means that this is too long to wait for a return on investment for these users.

The cost of conserved energy is also a useful indicator of the value of the investment into efficiency. Cost of conserved energy is given by 


$$
C C E=\frac{P}{\sum_{n=1}^{L} \frac{\Delta E}{(1+D R)^{n}}}
$$

In this formula, retail price $P$ appears in the numerator, where the denominator is energy savings $\Delta E$ over the life of the appliance, discounted in each year after purchase. CCE can be compared to electricity prices in order to judge cost-effectiveness. For commercial consumers, CCE is less than $3.00 \mathrm{Rs} / \mathrm{kWh}$, and therefore always lower than the commercial marginal rate of $4.80 \mathrm{Rs} / \mathrm{kWh}$. For residential consumers, it is below the current rate for the first four design options, and $2.80 \mathrm{Rs} / \mathrm{kWh}$ and $4.20 \mathrm{Rs} / \mathrm{kWh}$, respectively for design options 5 and 6 . The first of these is still below the cost of production of $3.50 \mathrm{Rs} / \mathrm{kWh}$, indicating that this level would be cost-effective if marginal tariffs were brought in line with the cost of production.

Finally Table 5 and Table 6 show the return on investment of each option, which indicates cost-effectiveness if this level is lower than the user discount rate. In general the efficiency options show very high rates of return, but they are lower than the residential discount rate in the case of the two highest efficiency options.

\section{National Energy Savings}

The cost-benefit analysis described in the previous section is a critical element of policy development and evaluation, because it assesses the appropriateness of efficiency targets in terms of impacts on individual consumers. It can also help identify additional opportunities for improvement. Ultimately, however, the goal of any efficiency program is to reduce growth in energy consumption and associated emissions of greenhouse gases and other pollutants at the national level. National energy impacts are evaluated by combining the market average efficiency improvement scenarios with projections of shipments. It takes into account the rate at which new, higher efficiency products will enter the stock by use of a retirement and replacement model.

\subsection{Efficiency Scenarios}

The first step in forecasting national level energy savings is to create a set of scenarios determining the market average efficiency of air conditioners in each year, from the implementation of the program (2007) to the end of the forecast period. We define the latter as 2030. National energy impacts are calculated by comparing total air conditioner electricity consumption in each scenario to the base case. In addition to the standards as defined, we have constructed scenarios that consider the possibility for additional improvements beyond those resulting from the program as currently defined. The scenario definitions are:

Base Case - In the 'Business as Usual' case, no improvements are made in the average market efficiency of air conditioners. This is a 'frozen efficiency' scenario - the market average remains constant at 2.36 EER throughout the forecast period.

MEPS Only - This case considers the impacts of minimum efficiency standards alone. Efficiency improvement is achieved exclusively by the removal of low-efficiency products as the standards are ratcheted over time. The impact of labels is not included in this scenario. The market average efficiency for this scenario is given in Table 3. 
MEPS + Labels - In this scenario, the efficiency levels for some models go beyond the requirement of MEPS. In 2007, we assume that the market will be divided evenly into one-, two- and three-star models, with the two and three star models just meeting the efficiency requirement of 2.5 and 2.7 EER respectively. In 2008, the one star models are eliminated. In this year, and 2009, we assume that the market is composed of 33\% 2.5 EER (two-star), $33 \%$ 2.7 EER (three-star) and 33\% at 2.8 EER (the minimum LCC level). Finally, in 2010 and beyond, the 2.5 EER will be eliminated. We then assume that the market will be divided evenly between models of 2.7 and 2.8 EER.

Minimum Life Cycle Cost - This scenario is very similar to the previous one, except that after 2010, all of the models are at the Minimum LCC level. Efficiency levels in this scenario are identical to the 'MEPS + Labels' scenario until 2010, at which point the entire market moves to $2.8 \mathrm{EER}$.

China 2009 Standard Example - This scenario describes the alternative of a 'reach' standard of $2.9 \mathrm{EER}^{8}$ in 2012, that is, the potential of additional savings if BEE supplemented its current scheme with a very stringent MEPS with two years lead time. As an example of such a stringent MEPS, we choose the upcoming reach standard to be implemented in China by 2009. Another way to view this scenario is as a harmonization with Chinese standards, with 3 years lag time. We assume that all models in 2012 and beyond will barely meet the standard. An efficiency level of 2.9 EER corresponds to design option 5 in Table 5 and Table 6 . According to the cost-benefit analysis, this efficiency level is cost-effective for commercial consumers, but not for residential consumers, given the current technology. The cost of conserved energy for this option is $2.78 \mathrm{Rs} . / \mathrm{kWh}$ for residential consumers. This is only slightly higher than the current marginal price of 2.7 Rs./kWh for these consumers, and is still well below the current cost of electricity production, which is $3.5 \mathrm{Rs} . / \mathrm{kWh}$. Therefore, it is easily imaginable that this option will become cost-effective to all consumers by 2012 due to manufacturer learning, economies of scale, or changes in the residential electricity tariff structures.

Each of these scenarios described above is shown in Figure 4.

\footnotetext{
${ }^{8}$ For window units only. The Chinese MEPS call for a level of 3.1 EER for split systems of 1.5T. For consistency we compare only to the level set for window units.
} 
Figure 4 - Market Evolution of Efficiency

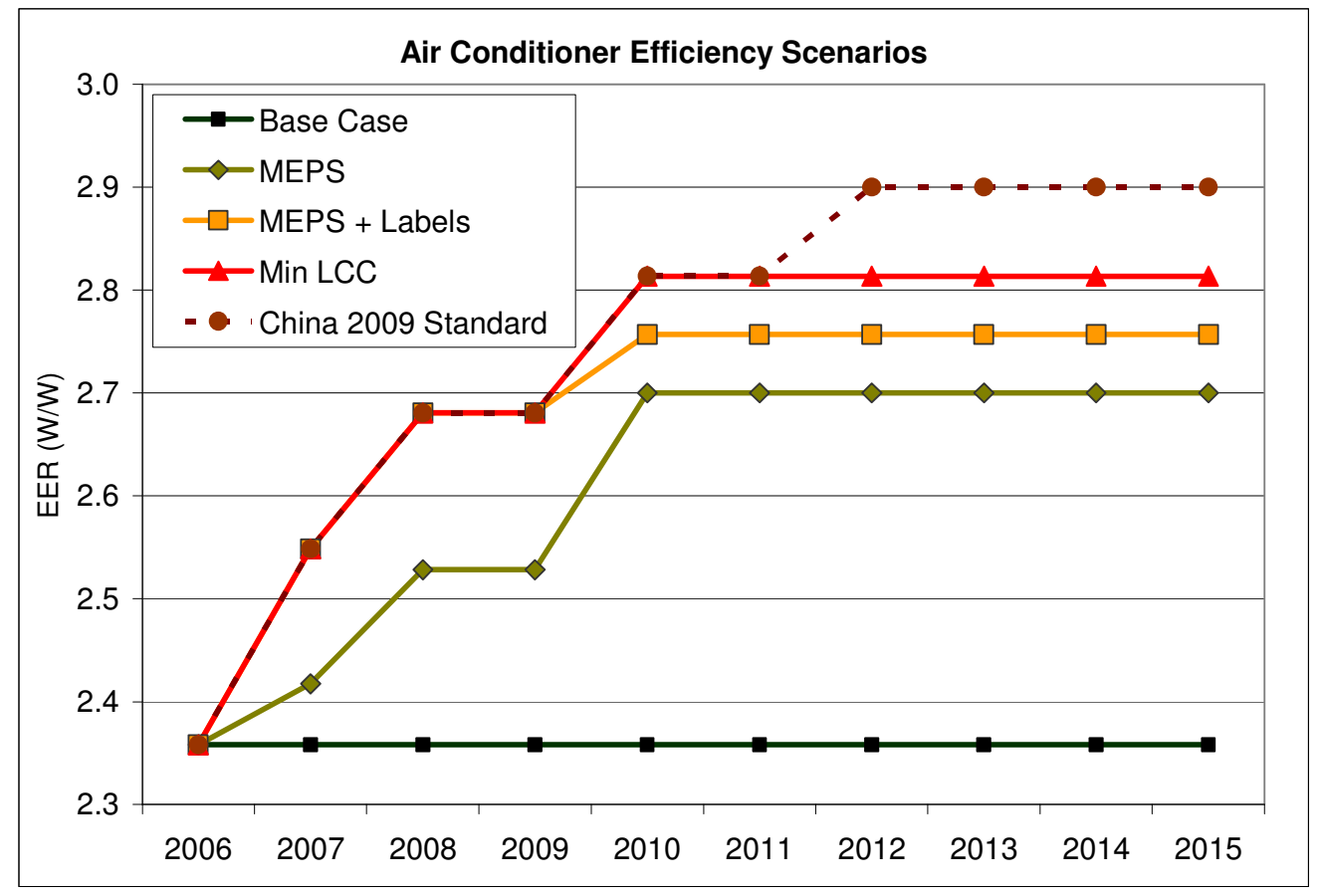

\subsection{Market Forecast}

The new and increasing residential customer base for air conditioners has caused dramatic growth in the industry in recent years at rates of more than $20 \%$ per annum, according to the Refrigeration and Air Conditioning Manufacturer's Association (RAMA). There is still great potential for growth in the residential sector, as household saturation rates are still around the $1 \%$ level. RAMA provided data to BEE for four years spanning 2003-2006, and including projections into 2007. These data include both the commercial and residential sectors, and give a good picture of current sales and growth rates. Growth rates are dramatic, as Table 7 shows. In addition, the fraction of the market estimated to be going to the residential sector is already high and growing rapidly. Growth peaked in 2003-2004 at $25 \%$, and has since come down a bit, to $20 \%$. The residential portion of the market grew from $50 \%$ to $58 \%$ percent over the data period.

Table 7 Air Conditioner Sales Data 2003-2006.

\begin{tabular}{|c|c|c|c|c|c|}
\hline & $\begin{array}{c}\text { Commercial } \\
\text { Market }\end{array}$ & $\begin{array}{c}\text { Residential } \\
\text { Market }\end{array}$ & Total & $\begin{array}{c}\text { Fraction } \\
\text { Residential }\end{array}$ & $\begin{array}{c}\text { Shipments } \\
\text { Growth Rate }\end{array}$ \\
\hline Year & Sales ('000) & Sales ('000) & Sales ('000) & Percent & Percent \\
\hline $2003-04$ & 500 & 500 & 1000 & $50 \%$ & \\
\hline $2004-05$ & 575 & 675 & 1250 & $54 \%$ & $25 \%$ \\
\hline $2005-06$ & 650 & 850 & 1500 & $57 \%$ & $20 \%$ \\
\hline $2006-07$ & 750 & 1050 & 1800 & $58 \%$ & $20 \%$ \\
\hline
\end{tabular}

While we believe the RAMA data to be accurate, a long term forecast based on recent years is difficult. The Indian economy is expected to grow rapidly over the next few decades, but it is hard to be sure whether the current extremely high rates will continue. Therefore, we 
take the conservative approach and assume that sales will continue to grow, albeit at a more moderate level. Specifically, we assume a $15 \%$ growth rate over the next few years, to 2010, after which we forecast that it will stabilize at $10 \%$ per annum. Shipments forecast according to these growth rates are shown in Figure 5. The fraction of widow shipments is estimated at $60 \%$ by RAMA, and is assumed to persist throughout the forecast ${ }^{9}$.

\section{Figure 5 Air Conditioner Shipments 2000-2050}

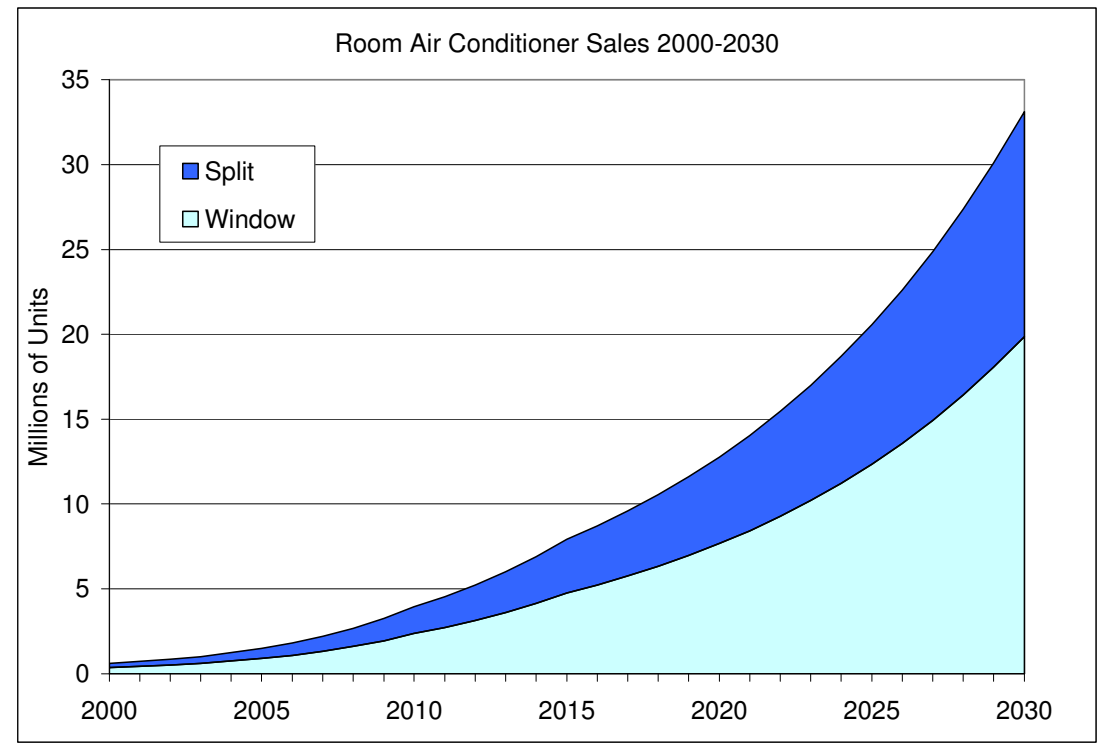

Shipments figures allow for an estimate of the total stock of air conditioners when combined with a retirement function. The retirement function we use is a simplistic one, but should be sufficiently accurate considering the uncertainty of other variables. We assume that the mean life of a room air conditioner in India is 15 years, and that units are retired and replaced with an equal probability between the $10^{\text {th }}$ and $20^{\text {th }}$ years after installation $^{10}$.

The size of the current stock of air conditioners is estimated by backcasting shipments to 1990 assuming a growth rate of $15 \%$ between 1990 and 2003. For the fraction of residential shipments, we use the RAMA estimates for available years; otherwise we assume a constant $2.5 \%$ relative growth rate in residential market fraction. The result of the stock calculation is an estimate of 2.8 million installed air conditioners in 2000, of which just over a million are used in homes. This is a rough estimate, but reasonable, since there are currently about 200 million households in India, and less than a percent of them use air conditioning. This situation changes dramatically over the forecast period. By 2020, we predict a residential stock of 61 million. Assuming an annual population growth rate of 1.3

\footnotetext{
${ }^{9}$ As stated above in section 2.1, comments from industry representatives in India indicate that the mini-split product class is gaining market share. This shift is difficult to forecast, however, and does not significantly impact forecasts of energy savings assuming equal relative improvements in the two product classes.

10 This is an approximate assumption, since repairs that significantly extend the lifetime of room air conditioners are common in India. The efficiency of extended-life units is expected to degrade. This is likely to affect baseline as well as high efficiency units, however. Therefore, while we acknowledge this point as having an impact on total consumption, we do not consider it has having a significant effect on net savings.
} 
percent, and no significant change in household size, we'd expect about 260 million households, giving a diffusion rate of $23 \%$, also reasonable considering that wealthier homes will probably own more than one air conditioner.

\subsection{National Energy Consumption}

When regulations take effect and are stepped up, the average efficiency of products sold increases, but products installed before the new rules become effective are not affected. The number of affected and unaffected stock in each year is tracked by a lifetime accounting model that considers the lifetime of the products and when old inefficient products are replaced with new more efficient ones. Energy savings is provided by calculating the total energy of the stock in the regulations scenario and comparing it to the base case, or 'business-as-usual' scenario. The total energy consumption (NEC) of the national stock of products in year $y$ is given by:

$$
\operatorname{NEC}(y)=\sum_{\text {age }} \operatorname{Stock}(y, \text { age }) \times U E C(y-\text { age })
$$

where the $U E C$ of each cohort is determined according to the year of purchase (y-age). $U E C$ is given for each scenario according to the following relationship:

$$
U E C^{\prime}(y)=U E C_{\text {Base }}(y) \times \operatorname{EER}(y)_{\text {Base }} / \operatorname{EER}(y)^{\prime}
$$

The $U E C$ in the base case is assumed to remain constant in time for each type of consumer, but decrease overall due to the growth in the fraction of air conditioners used in homes. The efficiency EER(y) for each scenario is shown in Figure 4. The results of the NEC for each scenario are shown in Figure 6.

\section{Figure 6 -Air Conditioner Electricity Consumption Scenarios}

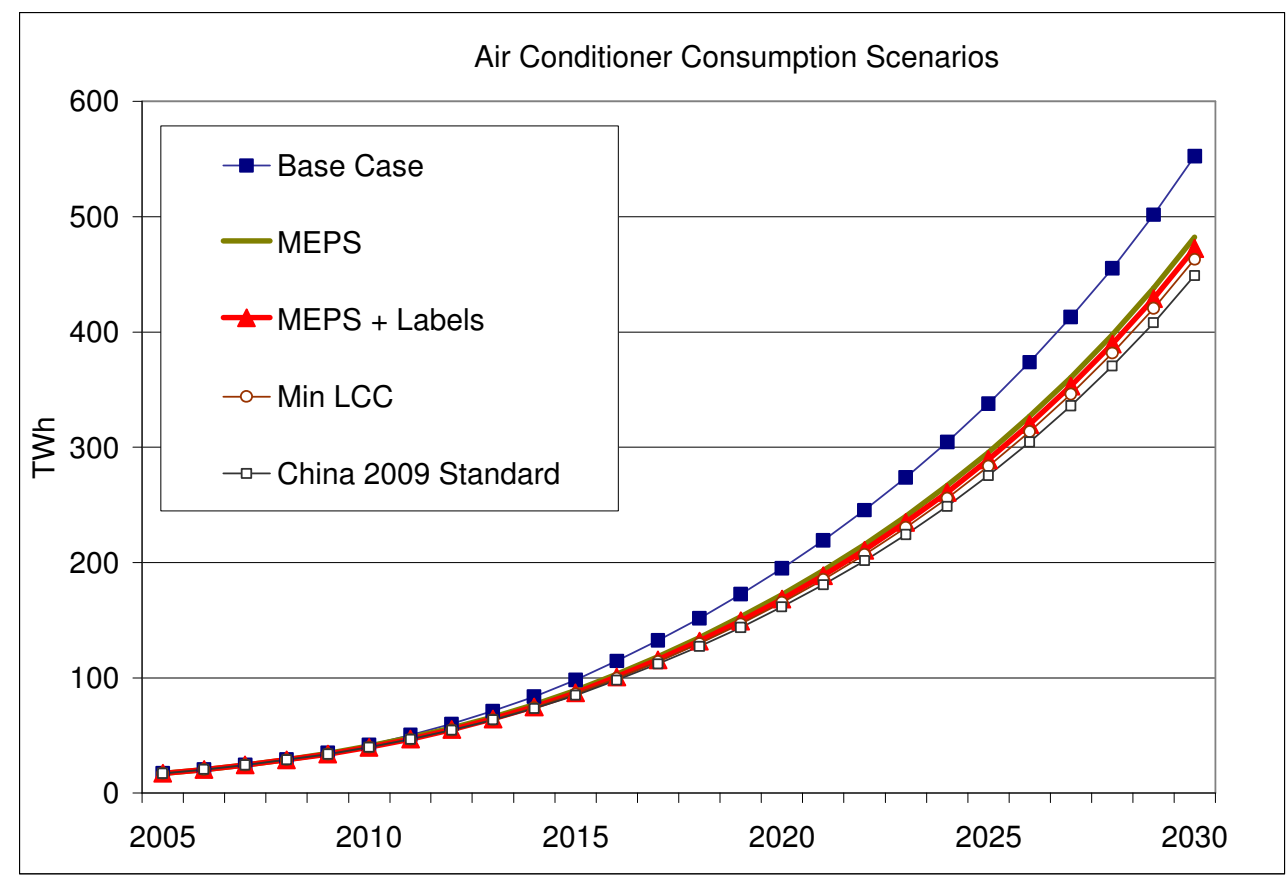


Several features may be noted from Figure 6 Most obvious is the dramatic growth in consumption that is expected to occur between 2005 and 2030. This growth arises from a simple extrapolation of current sales, and the assumption that sales growth will continue at relatively high rates, although much lower than current rates of $20 \%$ per year.

By 2020 most of the market will consist of units sold after the implementation of the MEPS and labeling program. Table 3 indicates that new units sold in 2010 will be on average 13\% more efficient than in the base case. By 2020, Table 8 shows that the MEPS Only scenario would bring total consumption down from $195 \mathrm{TWh}$ to $172 \mathrm{TWh}$, a savings of $22.7 \mathrm{TWh}$, or $11.6 \%$. This means that by 2020 the impacts on new unit improvements will have nearly completely encompassed the entire market. Savings for the MEPS+Labels scenario, and the Minimum LCC scenario are greater than the MEPS Only scenario, but only slightly so. This can be interpreted as an indication that the MEPS levels set by the program are sufficiently stringent to bring the entire market in line with the optimal efficiency level, viewed in terms of cost-effectiveness.

Finally, the China 2009 scenario saves $27 \%$ more electricity through 2030 than the $M E P S+$ Labels scenario. This would suggest that even with the relatively stringent standard set by BEE, there is significant opportunity for ratcheting beyond the 2010 period. As mentioned in above, in the current situation the 2.9 EER level is not cost-effective to residential consumers. Such a level could be reconsidered; however as part of a review in several years time, when manufacturer costs, and prevailing electricity tariffs may have changed.

Table 8 Site Energy Consumption and Savings 2010-2030

\begin{tabular}{|c|c|c|c|c|c|}
\hline & $\begin{array}{l}\text { Base } \\
\text { Case }\end{array}$ & MEPS & $\begin{array}{c}\text { MEPS + } \\
\text { Labels }\end{array}$ & Min LCC & $\begin{array}{l}\text { China } \\
2009\end{array}$ \\
\hline \multicolumn{6}{|c|}{ Energy Consumption (TWh) } \\
\hline 2010 & 42 & 41 & 40 & 40 & 40 \\
\hline 2020 & 195 & 172 & 168 & 165 & 162 \\
\hline 2030 & 552 & 482 & 472 & 463 & 449 \\
\hline \multicolumn{6}{|c|}{ Annual Energy Savings (TWh) } \\
\hline 2010 & & 1.1 & 2.1 & 2.1 & 2.1 \\
\hline 2020 & & 23 & 27 & 30 & 33 \\
\hline 2030 & & 70 & 80 & 89 & 103 \\
\hline \multicolumn{6}{|c|}{ Cumulative Energy Savings (TWh) } \\
\hline 2010 & & 1.7 & 3.6 & 3.6 & 3.6 \\
\hline 2020 & & 112 & 138 & 152 & 167 \\
\hline 2030 & & 572 & 666 & 742 & 845 \\
\hline
\end{tabular}

\subsection{Environmental Impacts}

Fuel inputs and carbon emissions savings are calculated from consumption avoided in the residence or business (site savings) according to three factors. These factors were calculated according to a detailed analysis of the Indian power sector and forecast capacity increases in a previous LBNL report. 
The first parameter is the heat rate, which is the amount of fuel needed to produce each $\mathrm{kWh}$ of electricity. This is a function of plant fuel type and efficiency. We estimate that fuel inputs in India are equal to 2.85 the electricity outputs, but that this rate will decrease to 2.7 by 2020 . Most of the plants built between now and 2020 will be thermal plants, which would tend to raise the overall heat rate. On the other hand, newer plants are likely to be much more efficient than the current generation capacity.

Primary energy consumption is calculated according to the heat rate forecast, and also takes into account $T \& D$ losses, which are currently large in India. We estimate these to be $28 \%$, but dropping to $20 \%$ by 2020 due to strong efforts on the part of government and private sector utilities to reduce losses.

Finally, the electricity carbon factor can also be calculated according to fuel inputs, in combination with a factor for each type of fuel. The current carbon factor is about $0.86 \mathrm{~kg}$ of carbon dioxide per $\mathrm{kWh}$ of electricity, but is expected to drop to $0.79 \mathrm{~kg} / \mathrm{kWh}$ by 2020 , reflecting a net gain due to improved efficiency of generation. The results of the conversion of site savings to primary savings and carbon dioxide emissions are shown in Table 9.

Table 9 Primary Energy and Emissions Savings 2010-2030

\begin{tabular}{|c|c|c|c|c|}
\hline & MEPS & $\begin{array}{c}\text { MEPS }+ \\
\text { Labels }\end{array}$ & Min LCC & $\begin{array}{c}\text { China } \\
2009\end{array}$ \\
\hline \multicolumn{5}{|c|}{ Annual Primary Energy Savings (PJ) } \\
\hline 2010 & 14 & 27 & 27 & 27 \\
\hline 2020 & 267 & 313 & 348 & 393 \\
\hline 2030 & 821 & 937 & 1049 & 1211 \\
\hline \multicolumn{5}{|c|}{ Cumulative Energy Savings (EJ) } \\
\hline 2010 & 0.02 & 0.05 & 0.05 & 0.05 \\
\hline 2020 & 1.4 & 1.7 & 1.8 & 2.0 \\
\hline 2030 & 6.8 & 7.9 & 8.8 & 10.0 \\
\hline \multicolumn{5}{|c|}{ Annual Emissions Mitigations (MT CO 2 ) } \\
\hline 2010 & 0.8 & 1.6 & 1.6 & 1.6 \\
\hline 2020 & 18 & 21 & 23 & 26 \\
\hline 2030 & 55 & 63 & 71 & 82 \\
\hline \multicolumn{6}{|c|}{ Cumulative Emissions Mitigations (MT $\mathrm{CO}_{2}$ ) } \\
\hline 2010 & 1.4 & 2.9 & 2.9 & 2.9 \\
\hline 2020 & 88 & 109 & 119 & 131 \\
\hline 2030 & 452 & 526 & 586 & 667 \\
\hline
\end{tabular}

\subsection{National Financial Impacts}

Finally, the shipments forecast, along with estimates of per unit equipment cost increases and utility bill savings allows for an assessment of national financial impacts for each scenario. In this calculation, only the direct net savings to consumers is considered, although there are other financial benefits due to Standards and Labeling programs. Some of these are:

- Reduced need for utilities to invest capital in construction of new power plants to meet increasing electricity demand. 
- Reduction of cross-subsidies to residential consumers from other sectors, or government subsidies.

- Decrease in power shortages and a subsequent increase in productivity and tax revenues.

The assessment of financial impacts to consumers follows the calculation of costeffectiveness and national energy impacts closely. Operating cost savings is built up from the national stock of products impacted by the regulations. Equipment cost impacts are built up from per-unit values, multiplied by the shipments of each product class in each year. In MEPS Only and MEPS+Labels scenario, the average efficiency improvement of products generally lies between definite design option levels. In order to estimate average incremental cost, therefore, we interpolate between levels according to the actual efficiency improvement indicated by Table 3 . Future investments and savings are discounted using a discount rate of $10 \%$. This is lower than the $12 \%$ or $15 \%$ rate used for Life Cycle Cost, because it represents the discount rate relevant to national investments (such as used, for example in national loans to improve power sector infrastructure), rather than a willingness to pay for individual consumers. Savings are discounted to 2006. The resulting Net Present Value of the investment in high efficiency equipment is shown in Figure 7 . In this calculation, no change in the prevailing marginal prices for electricity is assumed.

Figure 7 - Net Present Value of Savings due to Standards and Labeling Scenario

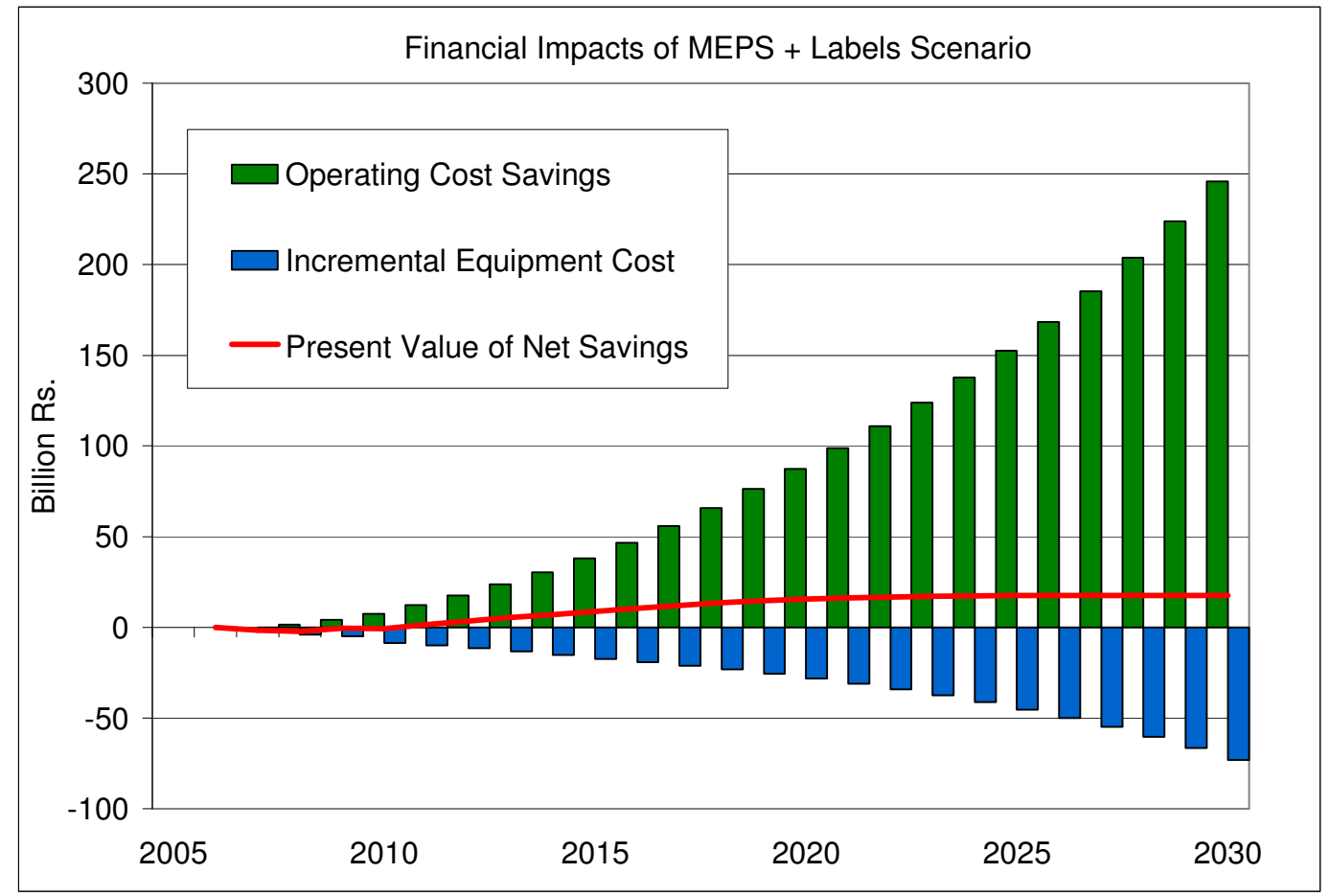

Cumulative Net Present Value are given in Table 10. This is perhaps the single most concise indicator of the value of the regulations to the Indian government. With MEPS and Labels as implemented, one might expect a net benefit to consumers of about 1400 billion rupees (about 31 billion \$US) from now to 2030. This corresponds to a present value of 260 billion rupees (about 5.7 billion \$US) when discounted at 10\%. As in the case of energy savings, the Minimum LCC scenario saves more money than the MEPS+Labels 
scenario, but only slightly. The China 2009 scenario saves $27 \%$ than the MEPS Labels scenario in terms of operating costs, but there is a considerable penalty from higher equipment costs, so that the NPV is only 82 billion Rs. This scenario still represents a positive investment for the nation as a whole, using a discount rate of $10 \%$. It must be remembered, however, that this option may not provide a net benefit to individual residential customers, whose discount rate we estimate at $15 \%$, and who typically will have lower operating cost savings than commercial customers.

Finally, these NPV calculations include consumer impacts only, not impacts to utilities. In particular, utilities will benefit from efficiency in the form of a net reduction of costs for customers with subsidized rates, and suffer a net loss from customers who paying more than the cost of electricity delivery. Due to the uncertainty in future tariff policies; however, we do not attempt a detailed analysis of utility impacts, here.

Table 10 - Cumulative NPV of Financial Impacts of Efficiency Scenarios

\begin{tabular}{|c|c|c|c|c|}
\hline \multicolumn{5}{|c|}{ Cumulative Net Present Value 2007-2030 (Billion Rs.) } \\
\hline & MEPS & $\begin{array}{c}\text { MEPS + } \\
\text { Labels }\end{array}$ & $\begin{array}{c}\text { Min } \\
\text { LCC }\end{array}$ & $\begin{array}{c}\text { China } \\
2009\end{array}$ \\
\hline Operating Cost Savings & 1817 & 2118 & 2358 & 2682 \\
\hline Incremental Equipment Cost & 531 & 698 & 849 & 2007 \\
\hline Net Savings & 1287 & 1419 & 1509 & 675 \\
\hline Discounted Net Savings & 233 & 260 & 272 & 82 \\
\hline
\end{tabular}

\section{Conclusions}

Overall, this analysis finds that the MEPS and labeling scheme announced by BEE is robust in comparison to prevailing policies in other countries, both industrialized and developing. Under this program, baseline air conditioner efficiency for window units is expected to approach that of current window unit markets in North America, Korea, and China by 2010. The cost-benefit analysis shows the chosen MEPS to be cost effective to both residential and commercial customers, and the 2010 level will approach the minimum Life-Cycle Cost design efficiency. Efficiency is likely to be boosted even closer to this level, or exceed it via the labeling program.

As part of the analysis, we considered the possibility of boosting MEPS even further, to harmonization with the recently announced Chinese level, which will come into effect in 2009. We find that this level would still be highly cost effective for commercial consumers, assuming they still pay high rates for electricity at the margin. However, this level may result in net financial penalties to residential consumers, unless manufacturer costs come down, or residential electricity tariffs are raised. There are several options that may allow for even higher efficiency for Indian air conditioners. First, the Government of India may implement higher standards even though some consumers may lose out, in order to avert a growing supply, and possibly as a disincentive to further growth in AC uptake. Alternatively, they could choose to subsidize consumer purchase of ultra-high efficiency equipment, through a rebate program. Further, they may continue to fully support the 
labeling program, with the idea that a significant fraction of consumers will view it as a benefit to purchase highly rated products ( 3 star and above).

We also note that the assessment of cost-benefit in terms of Cost of Conserved Energy provides a metric describing the interplay between efficiency policy, and policies determining electricity tariff schedules. We realize that tariff policies are very complex, and involve many other issues besides efficiency of individual products, but believe that they may be useful to policymakers, particularly for such an important product as air conditioners. The CCE for the highest level of technology we studied (3.3 EER), is 4.2 Rs per $\mathrm{kWh}$ for residential consumers. This level is above the current cost of production of 3.5 Rs per kWh. It is imaginable, however, that residential rates could be restructured such that baseline tariffs are still affordable, but the highest block (perhaps one reached only by customers with air conditioner loads) would be such to make this level of efficiency cost effective.

Finally, because the Indian air conditioner market looks to be transitioning from window to split units, attention will need to be paid to adjusting future standards to address the change in product types. Split unit standards in other countries are well above current window unit standards, indicating that it may be more cost-effective to attain higher efficiencies in split units than in window units. Assuming this is true, further efforts will need to be taken so that Indian standards for split units do not lag behind the standards in place in other countries.

\section{REFERENCES}

IMRB (2004). Baseline Report on Data Collected From Manufacturers, Indian Bureau of Energy Efficiency.

LBNL (2005) Potential Net Benefits from Improved Energy Efficiency of Key Electrical Products:The Case of India McNeil 2005 M.A. McNeil, M. Iyer, S. Meyers, V. E. Letschert and J. E. McMahon. Lawrence Berkeley National Laboratory. Berkeley, CA. 2005. LBNL Report Number 58254. 